\title{
Experimental study on horizontal bearing capacity of enlarged cap-group pile composite foundation
}

\author{
Taihao Chen ${ }^{*}$, Yiming $\mathrm{Xu}^{1}$, Jie Chen ${ }^{1}$ \\ ${ }^{1}$ Poly Changda Engineering Co., LTD, Guangzhou, GuangDong Province, 510003, China
}

\begin{abstract}
In order to provide reference for the engineering design in the area with large wind, water flow and other horizontal loads, the experimental study on the horizontal bearing capacity of composite foundation under three different working conditions was carried out in this paper, which includes cap-single pile, cap-9 piles and enlarged cap-9 piles. The results show that under the condition of cap-9 piles, the group pile effect coefficient is 1.17 , and the load sharing ratio of the back piles is the largest, and the middle and front piless decrease sequentially. Also, with the increase of horizontal load, the load sharing ratio of the back pile increases while the middle and front piless is decremented. Under the condition of enlarged cap-9 piles, the group pile effect coefficient is 1.36 , which is $16.24 \%$ higher than that of the cap-9 piles, which means the horizontal resistance is obviously enhanced. At the same time, compared with the cap- 9 piles, the load sharing ratio of the back pile is reduced while the middle and front piless is increased, which means the stress of pile body tends to be more uniform.
\end{abstract}

\section{Introduction}

In traditional design, cap-group pile composite foundation is mainly vertical bearing, but it is also subjected to horizontal loads in the actual engineering especially in coastal areas, such as wind, river and other horizontal loads, and engineering disasters caused by this often occur. At present, the corresponding research methods include theoretical research, experimental research and numerical analysis. The theoretical research includes elastic theory method, pile group efficiency method, and p-y curve reduction method [1-3]. The experimental research includes indoor model test, field test and centrifuge test [4-7]. The numerical analysis is mainly finite element [8-9]. Based on the above research methods, the scholars have carried out a series of studies on the horizontal bearing capacity of cap-pile [10-13], and some research results are valuable. But, the influence of cap size and group pile distribution style on the group pile effect still need further study. Therefore, the model test on horizontal bearing characteristics of cap-group pile with three different forms are carried out in the present paper, which in order to explore the influence of enlarged cap on the horizontal bearing capacity and group pile effect coefficient.

\section{Experimental design}

\subsection{Experimental soil}

This test relies on the Zhongshan west outer ring expressway project, and according to the actual situation, the silty clay is selected. The specific parameters of the test soil is shown in Table 1.

Tab.1 The specific parameters of test soil

\begin{tabular}{cccccc}
\hline$\gamma /\left(\mathrm{kN} / \mathrm{m}^{3}\right)$ & $\gamma_{d} /\left(\mathrm{kN} / \mathrm{m}^{3}\right)$ & $G_{s}$ & $\mathrm{~K} / \%$ & $E_{s} / \mathrm{MPa}$ & $\begin{array}{c}\varphi / \\
\left({ }^{0}\right)\end{array}$ \\
\hline 26.5 & 14.6 & 2.73 & 80 & 33 & 16 \\
\hline
\end{tabular}

\subsection{Model pile and cap}

The selection of model scale will influence the accuracy of test results and the size of deviation directly, so the accuracy and the practicability of operation is considered in the test, and the model scale of the test is determined to be 1:30. Meanwhile, compared with the design parameters of the Zhongshan west outer ring expressway project, the concrete of model pile is $\mathrm{C} 30$, and the diameter and length of model pile is $6 \mathrm{~cm}$ and $100 \mathrm{~cm}$ respectively. Two different pile spacing is adopted in the test, i.e., 2D $(12 \mathrm{~cm})$ and $4 \mathrm{D}(24 \mathrm{~cm})$. In the aspect of cap, the concrete is $\mathrm{C} 35$, and the thickness is $5 \mathrm{~cm}$. The steel screws are set up inside the cap to connect with the lower pile.

\subsection{Group pile arrangement}

To analyze the horizontal bearing capacity of enlarged cap-group pile composite foundation, three different 
cap-pile structures are adopted in the test, i.e., cap-single pile, cap-nine piles and enlarged cap-nine piles.

(1) cap-single pile

The design of cap-single pile is the foundation of the test, and the distance from the centre of the pile to the edge of the cap is the diameter of the pile.

(2) cap-nine piles

According to design specifications, the distance from the centre of side pile to the edge of the cap should not be less than the diameter or side length of the pile, and the layout of cap-nine piles is shown in figure 1, and the pile spacing is $2 \mathrm{D}$.

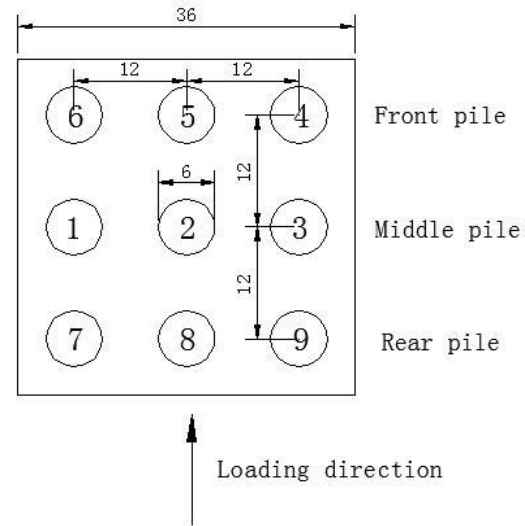

Figure.1 Layout of cap- nine piles (Unit: $\mathrm{cm}$ )

(3) enlarged cap-nine piles

The layout of cap-nine piles is shown in figure 2, and the pile spacing is $4 \mathrm{D}$.

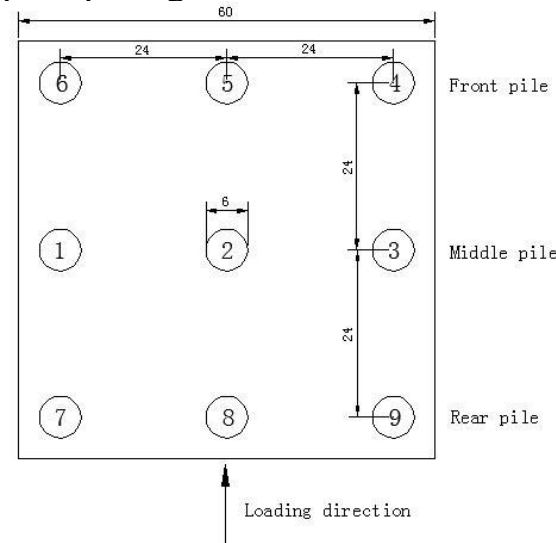

Figure.2 Layout of enlarged cap-nine piles (Unit: $\mathrm{cm}$ )

\subsection{Test plan}

In the present paper, the test with three different conditions will be carried out, and the parameters of three conditions are shown in Table 2.

Tab.2 The parameters of model test

\begin{tabular}{ccccc}
\hline $\begin{array}{c}\text { Condition } \\
\text { number }\end{array}$ & $\begin{array}{c}\text { Number } \\
\text { of piles }\end{array}$ & $\begin{array}{c}\text { Pile } \\
\text { length }\end{array}$ & $\begin{array}{c}\text { Cap } \\
\text { length/cm }\end{array}$ & $\begin{array}{c}\text { Cap } \\
\text { thickness/cm }\end{array}$ \\
\hline 1 & 1 & 100 & 12 & 5 \\
\hline 2 & 9 & 100 & 36 & 5 \\
\hline 3 & 9 & 100 & 60 & 5 \\
\hline
\end{tabular}

In the test, the horizontal load and horizontal displacement of each condition will be measured to obtain the corresponding ultimate horizontal bearing capacity. Meanwhile, the bending moment distribution of the pile under different horizontal loads will be obtained through the strain gauge attached to the pile, and the load bearing proportion of the pile at different positions can be calculated.

\section{Experimental results}

\subsection{Cap-single pile}

The curve of horizontal load and displacement of single pile is shown in figure 3 . It can be seen from figure 3 that the ultimate horizontal bearing capacity of single pile is $4.08 \mathrm{kN}$. The distribution curve of bending moment along the depth of single pile is shown in figure 4. From figure 4, we can conclude that under different horizontal load, the bending moment increases firstly and then decreases along the pile depth, which is approximately parabola distribution. Meanwhile, the maximum bending moment increases with the increase of horizontal load.

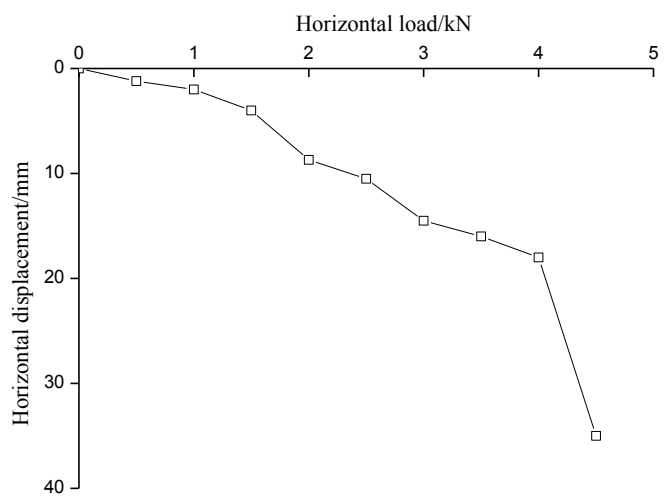

Figure.3 The Q-S curve of cap-single pile

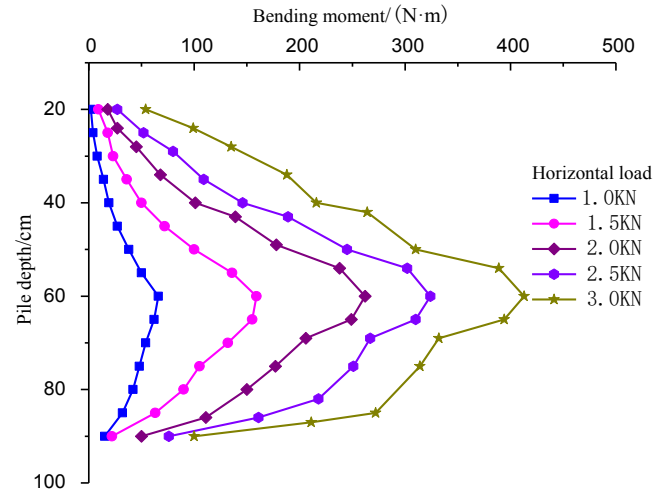

Figure.4 The bending moment of cap-single pile

\subsection{Cap-nine piles}

The curve of horizontal load and displacement of cap-nine piles is shown in figure 5, and we can see that the ultimate horizontal bearing capacity of cap-nine piles is $44.48 \mathrm{kN}$. The calculation formula of effect coefficient of pile group is

$$
\eta=H /\left(n \times H_{0}\right)
$$


where $\eta$ is the effect coefficient of pile groups, $H$ is the horizontal bearing capacity of group piles, $H_{0}$ is the horizontal bearing capacity of single pile, $n$ is the quantity of pile in group piles.

By Eq. (6), we can calculate the effect coefficient of cap-nine piles, i.e., $\eta=42.98 /(9 \times 4.08)=1.17$. So we can know that compared with single pile, the horizontal bearing capacity of each pile in the cap-nine piles increases by $17 \%$. In the aspect of bending moment, take the central pile of cap-nine piles for example, the bending moment distribution under different horizontal loads is shown in Figure6. We can see that compared with the cap-single pile, the maximum bending moment decrease.
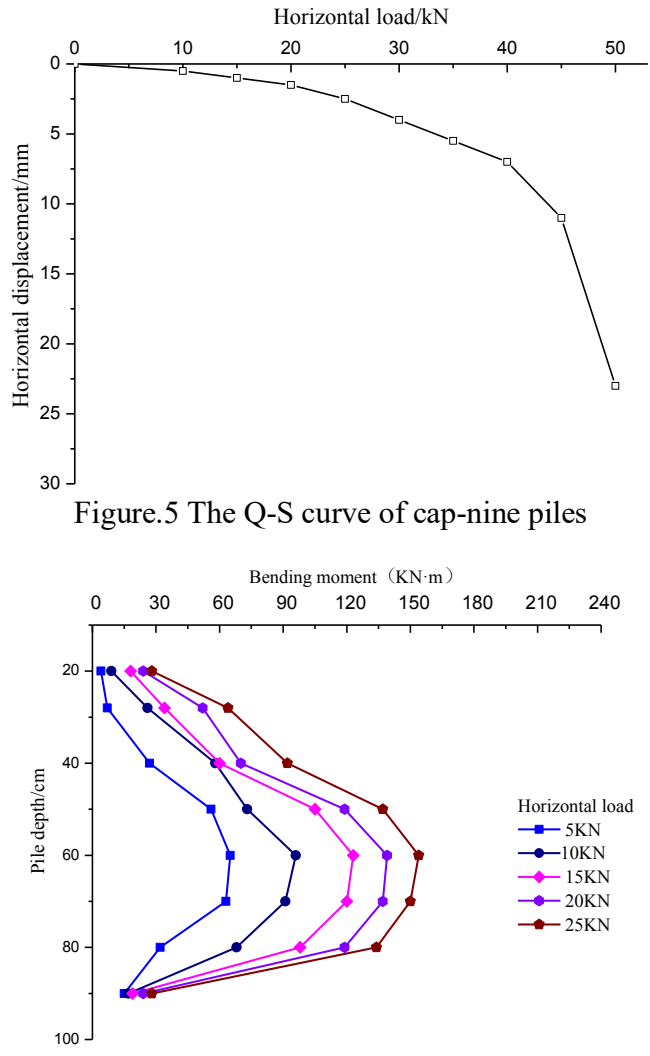

Figure.6 The bending moment of cap-nine piles

By calculating the force of each pile, we can get the horizontal load sharing ratio of front piles, middle piles and rear piles, which is shown in figure 7. It can be seen from Figure 7 that the horizontal load sharing ratio of rear piles is the largest all the time, while the front piles is the smallest. Furthermore, with the increase of horizontal load, the horizontal load sharing ratio of rear piles increase gradually, while the middle piles and front pile decrease gradually.

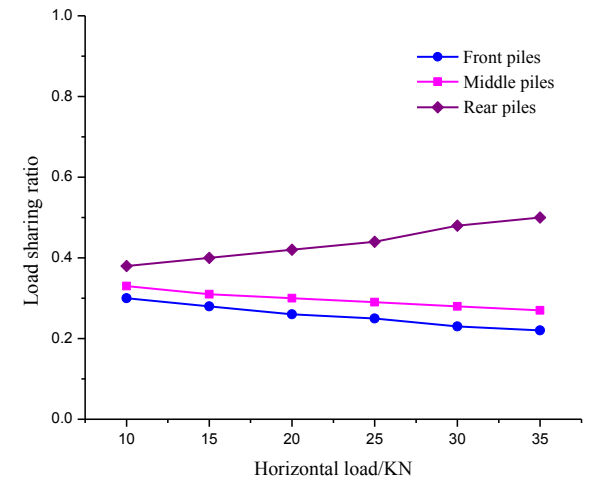

Figure.7 The load sharing ratio curve of cap-nine piles

\subsection{Enlarged cap-nine piles}

The curve of horizontal load and displacement of enlarged cap-nine piles is shown in figure 8 , and we can see that the ultimate horizontal bearing capacity of cap-nine piles is $50.06 \mathrm{kN}$, so the effect coefficient of enlarged cap-nine piles is 1.36 . Compared with cap-nine piles, the effect coefficient increases by $16.24 \%$, which is mainly due to the constraint effect of enlarged cap. Similarly, take the central pile of enlarged cap-nine piles for example, the bending moment distribution is shown in Figure 9. By comparing with figure 6, we can see that the position of the maximum bending moment move up, which is similar to that of cap-single pile.

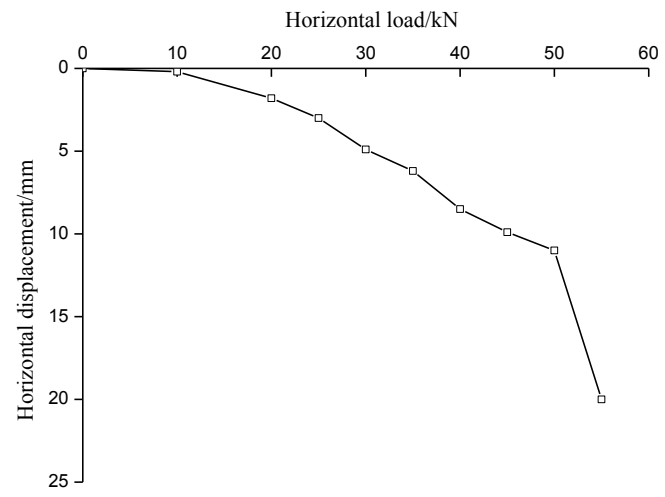

Figure.8 The Q-S curve of enlarged cap-nine piles

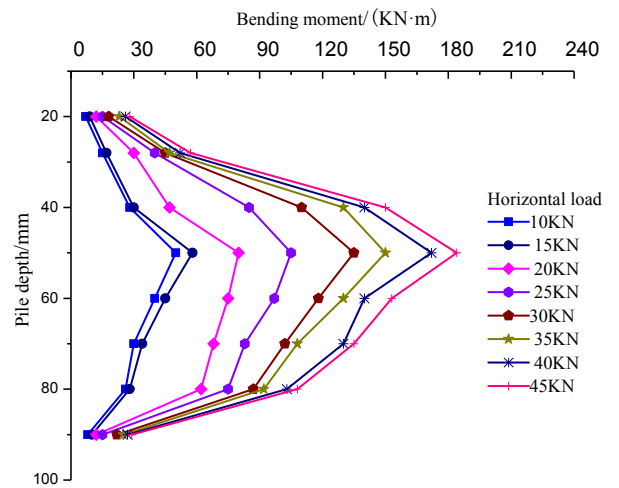

Figure. 9 The bending moment of enlarged cap-nine piles

Similarly, we can calculate the horizontal load sharing ratio of front piles, middle piles and rear piles, which is shown in Figure10. By comparing with figure 7, we can see that the change trend and size relationship of front piles, middle piles and rear piles are the same, but 
the value of rear piles decreases, while that of front piles and middle piles increase. In other words, the force of group piles is more uniform.

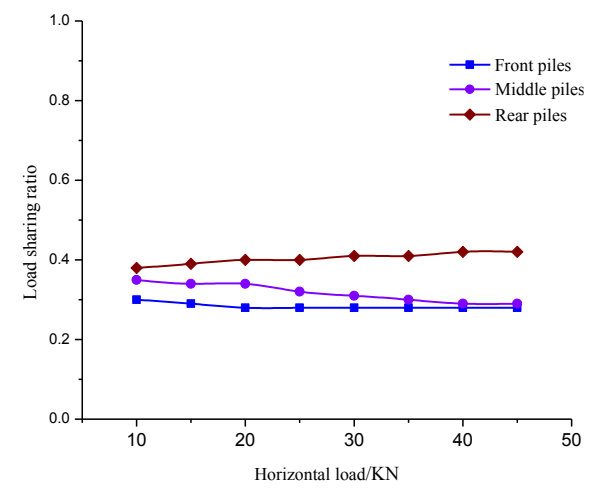

Figure.10 The load sharing ratio curve of enlarged cap-nine piles

\section{Concluding remarks}

In this work, we get that effect coefficient of cap-nine piles is 1.17 , while that of enlarged cap-nine piles is 1.36 , which means with the increase of pile spacing, the horizontal bearing capacity of each pile improve. Meanwhile, with the increase of pile spacing, the maximum bending moment of each pile decrease, and the position of that moved up. On the other hand, the force of piles in different positions are greatly different, i.e., the load sharing ratio gradually reduce along the direction of the horizontal force. But with the increase of pile spacing, the gap of load sharing ratio decrease gradually, which means the force of piles in different position is more uniform. Therefore, in the actual engineering design, we can improve and optimize the horizontal bearing capacity of the cap-group piles composite foundation by increasing the pile spacing.

\section{References}

1. Polous, H. G., Davis, E. H. (1980) Pile foundation analysis and design. New York: Wiley.

2. Bian X Y, Zheng J J, Xu Z J. (2014) Resistance coefficient of pile group foundation and safety factor reliability design. Journal of Huazhong University of Science and Technology (Natural Science Edition), 42: 87-91.

3. Brown D A, Morrison C, Reese L C. (1988) Lateral Load Behavior of Pile Group in Sand. Journal of Geotechnical Engineering, 114:1261-1276.

4. Feng J, Zhang J Y, Zhu M. (2016) The research for transverse bearing characteristics of pile Group Foundation of Bridge groups with High cap pile in soft soil. Geotechnical mechanics, 37: 94-104.

5. Wang H, Zhou J, Deng Z H. (2006) The research for model test on pile-soil-cap pile combined action. Journal of Geotechnical Engineering, 28: 1253-1258.
6. Ruesta, P F, Townsend, F C. (1997) Evaluation of laterally loaded pile group. ASCE Journal of Geotechnical and Geoenvironmental Engineering, 123:1153-1174.

7. Zhang Y T. (2018) The research for centrifugal model for interaction between pile groups and soft clay which is under horizontal cyclic load. Waterway port, 39: 211-216.

8. Ai Z Y, Li Z X. (2016) Horizontal vibration response of pile groups in layered transversely isotropic soil which under the action of wash. Chinese Journal of geotechnical engineering, 38: 613-618.

9. Xiong H, Jiang Y F, Li E. (2017) Simplified finite element calculation for dynamic impedance of pile groups-soil interaction. Journal of Railway Science and Engineering, 14: 928-934.

10. Zhang M Y, Lu Z H, Yang J B. (2016) The test for horizontal bearing capacity of large diameter rigid pile under the action of bending and shearing of soft soil. Journal of Tongji University (Natural Science Edition), 44: 1166-1172.

11. Chen Y D, Wang X D, Zai J M. (2011) The Model test and numerical simulation which visualization of soil displacement field under the pile group cap. Journal of Sichuan University (Engineering Science Edition), 43:45-51.

12. Guo C, Fu B Y, Yuan H. (2016) The research for the application and field measurement of bridge reverse operation the cap pile and the pile group composite foundation. Journal of Geotechnical Engineering, 38: 2085-2092.

13. He Z Y, Ye A Y. (2014) Influence of the group pile effect for seismic performance of pile group foundation with high pile cap in sand foundation. Journal of Civil Engineering, 47: 117-126. 